Whitwell et al quote a frequency of adenocarcinoma, which often presents with metastases, of $2 \%$ in a biopsy series and of $28 \%$ in a necropsy series. This may partly explain the small numbers of adenocarcinomas in our series, but the numbers were too small for firm conclusions.

Warnock and Churg, ${ }^{9}$ in a necropsy study of lungs, found significantly higher levels of ferruginous bodies in patients with carcinoma and concluded that even extremely low levels of asbestos exposure may have a carcinogenic effect. Their work can be questioned on the basis of a lack of detailed occupational history, but their conclusions agree with ours.

The implementation of the asbestos regulations may have largely eliminated the occupational risk for workers in scheduled industries, ${ }^{11}$ but our findings show that there is a risk for those whose occupation may not be primarily associated with asbestos. It is among these workers, numerically an important group, that asbestos-induced disease will probably be found in the future. The degree and the length of exposure to asbestos that is carcinogenic is something that is not established. Small amounts of asbestos can be found in the lungs at routine necropsies, ${ }^{6}{ }_{11}^{12}$ and it is unlikely that very small amounts of inhaled asbestos increase the risk of cancer. Our figures are consistent with the hypothesis that the risk of cancer is related to dose and duration of exposure and with the possibility that there is a safe lower limit.

The increasing use of asbestos and the comparatively long latent interval between exposure and neoplasia ${ }^{13}{ }^{14}$ suggest that the incidence of "asbestos cancer" will increase. Malignant pleural mesothelioma is now accepted as resulting from comparatively short exposure to comparatively small amounts of asbestos, usually many years before the appearance of the tumour. We must now seek diligently for possible previous exposure to asbestos in all cases of bronchial carcinoma.

We thank the physicians of the general hospitals in Ashington, Bishop Auckland, Chester-le-Street, Durham, Gateshead, Newcastle upon Tyne, and South Shields for allowing us to interview patients under their care and Miss M R Sanderson and Mrs M B Thompson for technical help.

\section{References}

${ }^{1}$ Lynch, K M, and Smith, W A, American fournal of Cancer, 1935, 24, 56

- Berry, G, Newhouse, M L, and Turok, M, Lancet, 1972, 2, 476.

${ }^{3}$ Enterline, $\mathrm{P}$, de Coufle, $\mathrm{P}$, and Henderson · V, British fournal of Industrial Medicine, 1973, 30, 162 .

4 Royal College of Physicians, Smoking and Health Now, London, Pitman Medical, 1971.

${ }^{5}$ Woolf, B, Annals of Human Genetics, 1955, 19, 251.

${ }^{6}$ Doniach, I, Swettenham, K V, and Hathorn, M K S, British fournal of Industrial Medicine, 1975, 32, 16.

' Selikoff, I J, Hammond, E C, and Churg, J, Journal of the American Medical Association, 1968, 204, 106.

* Whitwell, F, Newhouse, M L, and Bennett, D R, British fournal of Industrial Medicine, 1974, 31, 298.

9 Warnock, M L, and Churg, A M, Cancer, 1975, 35, 1236.

${ }^{10} \mathrm{Knox}, \mathrm{J}$ F, et al, British fournal of Industrial Medicine, 1968, 25, 293.

${ }^{11}$ Cauna, D, Totten, R S, and Gross, P, fournal of the American Medical Association, 1965, 192, 371

${ }^{12}$ Ashcroft, T, British Medical fournal, 1968, 1, 614.

${ }^{13}$ O'Donnell, W M, Mann, R H, and Grosh, J L, Cancer, 1966, 19, 1143.

${ }^{14}$ Selikoff, I J, et al, American fournal of Medicine, 1967, 42, 487.

(Accepted 10 fanuary 1977)

\title{
Maintenance digoxin after an episode of heart failure : placebo-controlled trial in outpatients
}

\author{
SYLVIA M DOBBS, W I KENYON, R J DOBBS
}

British Medical fournal, 1977, 1, 749-752

\section{Summary}

The need for maintenance digoxin treatment was assessed in a double-blind, variable-dose, crossover comparison with placebo. Forty-six outpatients who had been prescribed the drug for heart failure were studied; 33 were in sinus rhythm and the remainder in atrial fibrillation. Mean serum digoxin concentrations in those with sinus rhythm averaged $1.33 \mathrm{nmol} / \mathrm{l}$, but a lower concentration, averaging $0.97 \mathrm{nmol} / 1$, was accepted in those with atrial fibrillation as six of them developed bradycardia. Sixteen of the 46 patients deteriorated on placebo, and eight completely recovered when digoxin

\footnotetext{
Department of Pharmacology, Materia Medica and Therapeutics, University of Manchester, Manchester M13 9PT

SYLVIA M DOBBS, MB, MSC, honorary research fellow at Tameside General Hospital (Present address: Department of Pharmacology and Therapeutics, Middlesex Hospital Medical School, London).

Tameside General Hospital, Ashton-under-Lyne, Lancashire W I KENYON, FRCP, consultant physician

University College Hospital Medical School, London R J DOBBS, DCH, MRCP, research fellow
}

was reintroduced; in the remainder additional diuretics were required temporarily. Spirometric values deteriorated on changing to placebo whether or not the patient showed clinical evidence of recurrence of heart failure.

In a separate study of nine patients who showed no clinical evidence of deterioration on placebo, reintroduction of digoxin caused a shortening of left ventricular ejection time, which persisted for at least a month. This suggests that the inotropic response to digoxin is sustained during maintenance treatment.

\section{Introduction}

Traditionally, once a patient has been digitalised for heart failure treatment is continued indefinitely. There is, however, a substantial risk of toxicity should renal function deteriorate ${ }^{1}$ or the severity of the heart disease increase. ${ }^{2-4}$ It is therefore important to determine whether patients benefit from such treatment.

Rogen $^{5}$ found that withdrawal of digoxin resulted in decompensation and tachycardia in over three-quarters of a group of patients in atrial fibrillation with a history of cardiac failure. In contrast Dall ${ }^{6}$ found that the drug could be withdrawn in almost three-quarters of a group in sinus rhythm, although many had no known cardiac lesion. We assessed the need for continuous treatment in clinically stable outpatients, who were either in sinus rhythm or in atrial fibrillation with no history of 
the ventricular rate exceeding 120/minute. Digoxin had been prescribed initially for heart failure.

\section{Patients and methods}

Sixty-three patients with sinus rhythm or atrial-fibrillation and no history of the ventricular rate exceeding 120/minute presented during the study period, and 46 were clinically stable. Thirteen of the 46 were in atrial fibrillation. Digoxin had been started for left ventricular failure in 27 , cor pulmonale in 10 , and congestive cardiac failure in nine. The causes of failure were ischaemic heart disease (in 18 patients), rheumatic heart disease (11), chronic bronchitis and emphysema (10), hypertension (5), cardiomyopathy (1), and systemic lupus erythematosus (1). Twenty-eight patients were receiving diuretics. All participants gave informed consent.

Digoxin tablets (Lanoxin) were dispensed in calendar packs. ${ }^{7}$ Daily doses of $0.125 \mathrm{mg}, 0.1875 \mathrm{mg}, 0.25 \mathrm{mg}, 0.375 \mathrm{mg}$, or $0.5 \mathrm{mg}$ were taken at $10 \mathrm{am}$. Placebo tablets were dispensed in identical packs. In each patient the dose was titrated against the serum concentration to achieve a level close to $1.3 \mathrm{nmol} / 1(1.0 \mathrm{ng} / \mathrm{ml})$ just before the dose was given (corresponding mean steady state ${ }^{8}$ concentration $1.8 \mathrm{nmol} / 1$ $\left.(1.4 \mathrm{ng} / \mathrm{ml})^{9}\right)$. At this concentration six "slow fibrillators" developed bradycardia, and two patients in sinus rhythm developed symptoms of toxicity. They were then given the largest tolerated dose.

Patients who had been clinically stable for three months on the selected dose were randomly allocated to either digoxin or placebo, and after six weeks their treatment was crossed over. Whenever possible any other treatment remained unchanged.

At each visit patients filled in a questionnaire and were examined by a doctor who was unaware of their treatment (table 1). He graded the patients according to the New York Heart Association functional classification. Body weight, a 12-lead electrocardiogram, forced expiratory volume $\left(\mathrm{FEV}_{1}\right)$, and vital capacity $(\mathrm{FVC})$ were recorded and a chest $x$-ray film was taken at the end of the run-in period and after both phases of the trial. Venous blood for digoxin assay ( $\beta$ Lanoxitest) was taken twice during each phase of the trial, just before the daily dose was given. Serum sodium, potassium, calcium, bicarbonate, and creatinine clearance were also measured during each phase.

Precautions-A second clinician, aware of the treatment and the clinical condition of each patient, brought forward investigations and restarted active treatment when indicated. Patients were instructed to contact the hospital should there be any change in their health.

Systolic time intervals-Left ventricular systolic time intervals were subsequently studied in nine patients in sinus rhythm who were randomly selected from those who did not deteriorate on placebo. Simultaneous recordings of the electrocardiogram, phonocardiogram, and carotid pulse were made after one month on each treatment. The following were measured directly: total electromechanical systole $\left(\mathrm{QS}_{2}\right)$, left ventricular ejection time (LVET), and the time from the first to the second heart sound $\left(S_{1} S_{2}\right)$. The pre-ejection period (PEP) and its components (the isovolumic contraction time (ICT) and the time from the beginning of depolarisation to the first heart sound (Q-1) ) were calculated as follows ${ }^{10}$ :

$$
\begin{aligned}
\mathrm{PEP} & =\mathrm{QS}_{2}-\text { LVET } \\
\mathrm{ICT} & =\mathrm{S}_{1} \mathrm{~S}_{22}-\mathrm{LVET} \\
\mathrm{Q}-1 & =\mathrm{QS}_{2}-\mathrm{S}_{1} \mathrm{~S}_{2}
\end{aligned}
$$

The heart rate was obtained from the average $R-R$ interval.

Analysis-Records were analysed by a third clinician, who was not concerned in the running of the trial. Patients who deteriorated clinically on placebo were classified as group 1, the remainder as group 2. Paired Student's $t$ tests were used to compare clinical measurements made in the digoxin phase with those made in the placebo phase in each group. The characteristics of the patients in groups 1 and 2 were compared using unpaired $t$ tests for parametric data, and a $\%^{2}$ test with Yates's correction or Fisher's exact test was

\begin{tabular}{|c|c|c|c|c|c|}
\hline Signs & Grade & Definition & Symptoms & Grade & Definition \\
\hline (a) Gallop rhythm & $\frac{1}{2}$ & $\begin{array}{l}\text { Absent } \\
\text { Present }\end{array}$ & $\begin{array}{l}\text { (a) Orthopnoea } \\
\text { (No of pillows used) }\end{array}$ & $\begin{array}{l}1 \\
2 \\
3\end{array}$ & $\begin{array}{l}<3 \\
\text { Between grades } 1 \text { and } 3 \\
\text { Enough to prop patients up at } 90^{\circ}\end{array}$ \\
\hline (b) Jugular venous pulse & $\begin{array}{l}1 \\
2 \\
3\end{array}$ & $\begin{array}{l}2 \mathrm{~cm} \\
\text { Between grades } 1 \text { and } 3 \\
\text { To angle of jaw }\end{array}$ & $\begin{array}{l}\text { (b) Nocturnal dyspnoea } \\
\text { (No of episodes/week) }\end{array}$ & $\begin{array}{l}1 \\
2 \\
3\end{array}$ & $\begin{array}{l}\text { None } \\
\text { Occasional } \\
\text { Every night }\end{array}$ \\
\hline (c) Oedema & $\begin{array}{l}1 \\
2 \\
3\end{array}$ & $\begin{array}{l}\text { Absent } \\
\text { Between grades } 1 \text { and } 3 \\
\text { Constantly present }\end{array}$ & $\begin{array}{l}\text { (c) Ability to climb stairs } \\
\text { (No of flights (12 steps) } \\
\text { climbed without stopping) }\end{array}$ & $\begin{array}{l}1 \\
2 \\
3\end{array}$ & $\begin{array}{l}<2 \\
1<1\end{array}$ \\
\hline (d) Central cyanosis & $\begin{array}{l}1 \\
2\end{array}$ & $\begin{array}{l}\text { Absent } \\
\text { Present }\end{array}$ & $\begin{array}{l}\text { (d) Ability to walk briskly on flat } \\
\text { (Distance walked without }\end{array}$ & $\begin{array}{l}1 \\
2\end{array}$ & $=100$ yards $(\geqslant 91 \mathrm{~m})$ \\
\hline (e) Tender hepatomegaly & $\begin{array}{l}1 \\
2\end{array}$ & $\begin{array}{l}\text { Absent } \\
\text { Present }\end{array}$ & stopping) & 3 & $<50$ yards $(<45.7 \mathrm{~m})$ \\
\hline (f) Pulmonary oedema & $\begin{array}{l}1 \\
2 \\
3\end{array}$ & $\begin{array}{l}\text { Absent } \\
\text { Between grades } 1 \text { and } 3 \\
\text { Extensive crepitations }\end{array}$ & & & \\
\hline (g) Bronchospasm & $\begin{array}{l}1 \\
2\end{array}$ & $\begin{array}{l}\text { Absent } \\
\text { Present }\end{array}$ & & & \\
\hline
\end{tabular}
used for non-parametric data.

TABLE I-Clinical signs and symptoms that were assessed in eack patient

\begin{tabular}{|c|c|c|c|c|c|c|c|c|c|c|c|c|}
\hline \multirow{2}{*}{$\begin{array}{l}\text { Case } \\
\text { No }\end{array}$} & \multicolumn{4}{|c|}{ Symptom* } & \multirow{2}{*}{$\begin{array}{l}\text { Functional } \\
\text { classification }\end{array}$} & \multicolumn{7}{|c|}{ Sign* } \\
\hline & $a$ & $b$ & $c$ & $d$ & & $a$ & $\bar{b}$ & $c$ & $\bar{d}$ & $e$ & $f$ & $g$ \\
\hline $\begin{array}{r}3 \\
8 \\
9 \\
10 \\
15 \\
18 \\
25 \\
32 \\
35 \\
36 \\
38 \\
39 \\
42 \\
43 \\
44 \\
45\end{array}$ & $\begin{aligned} & \overline{-} \\
& 1 \rightarrow 3(\mathrm{P}) \\
& 1 \rightarrow 2(\mathrm{~T}) \\
& \overline{-} \\
& 2 \rightarrow 3(\mathrm{~T}) \\
& 1 \rightarrow 3(\mathrm{~T}) \\
& 2 \rightarrow 3(\mathrm{~T}) \\
& 1 \rightarrow 2(\mathrm{~T}) \\
&= \\
&= \\
&=\end{aligned}$ & $\begin{array}{c}\quad \overline{-} \\
1 \rightarrow 3(\mathrm{~N}) \\
1 \rightarrow 2(\mathrm{~T}) \\
2 \rightarrow 3(\mathrm{~T}) \\
2 \rightarrow \overline{3}(\mathrm{~T}) \\
1 \rightarrow 2(\mathrm{~T}) \\
1 \rightarrow 3(\mathrm{~T}) \\
= \\
\overline{-} \\
1 \rightarrow 2(\mathrm{~T}) \\
\overline{-} \\
2 \rightarrow 3(\mathrm{~T})\end{array}$ & $\begin{array}{c}2 \rightarrow \overline{3}(\mathrm{~T}) \\
\bar{z} \\
\overline{-} \\
2 \rightarrow \overline{3(\mathrm{~N})} \\
1 \rightarrow 3(\mathrm{~T}) \\
1 \rightarrow \overline{2}(\mathrm{~T}) \\
\bar{Z} \\
\bar{Z} \\
1 \rightarrow 2(\mathrm{~T})\end{array}$ & $\begin{array}{l}= \\
= \\
= \\
= \\
= \\
= \\
= \\
=\end{array}$ & $\begin{array}{c}\quad-\overline{4}(\mathrm{~T}) \\
3 \rightarrow 2(\mathrm{~T}) \\
1 \rightarrow \rightarrow(\mathrm{T}) \\
3 \rightarrow 4(\mathrm{~T}) \\
2 \rightarrow 3(\mathrm{~T}) \\
3 \rightarrow 4(\mathrm{~T}) \\
1 \rightarrow 2(\mathrm{~T}) \\
1 \rightarrow 2(\mathrm{~T}) \\
= \\
= \\
1 \rightarrow 2(\mathrm{~T})\end{array}$ & $\begin{array}{c}1 \rightarrow 2(\mathrm{~T}) \\
= \\
= \\
= \\
= \\
= \\
= \\
= \\
=\end{array}$ & 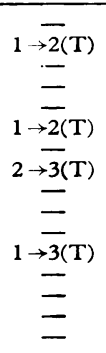 & $\begin{array}{c}1 \rightarrow 3(\mathrm{~T}) \\
= \\
= \\
= \\
= \\
= \\
= \\
=\end{array}$ & $\begin{array}{c}= \\
= \\
= \\
\bar{z} \\
= \\
= \\
= \\
= \\
=\end{array}$ & $\begin{array}{l}= \\
= \\
= \\
= \\
= \\
= \\
= \\
= \\
=\end{array}$ & $\begin{aligned} 1 & \rightarrow 2(\mathrm{~N}) \\
1 & \rightarrow 2(\mathrm{~T}) \\
1 & \rightarrow 3(\mathrm{~T}) \\
2 & \rightarrow 3(\mathrm{~N}) \\
2 & \rightarrow 3(\mathrm{~T}) \\
1 & \rightarrow 2(\mathrm{~T}) \\
& -3(\mathrm{P}) \\
1 & \rightarrow 2(\mathrm{~T}) \\
& - \\
1 & \rightarrow 2(\mathrm{~T}) \\
2 & \rightarrow 3(\mathrm{~N}) \\
1 & \rightarrow 2(\mathrm{~T}) \\
1 & \rightarrow 2(\mathrm{~N}) \\
1 & \rightarrow 2(\mathrm{~N})\end{aligned}$ & 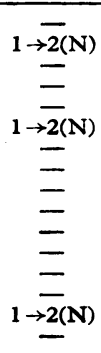 \\
\hline
\end{tabular}

Blood pressure, resting pulse and apex rate, and body weight were also measured.

TABLE II-Clinical deterioration on placebo

*See table I for definition of grades. Numbers before and after arrows indicate grade before and during placebo phase.
$-=$ No change. $(T)=$ Rapid total recovery after restarting digoxin. $(P)=$ Partial recovery. $(N)=$ No improvement. 


\section{Results}

The mean predose serum digoxin concentration $( \pm 1 \mathrm{SD})$ during the active phase was $1.33 \pm 0.29 \mathrm{nmol} / 1(1.04 \pm 0.23 \mathrm{ng} / \mathrm{ml})$ in patients in sinus rhythm and $0.97 \pm 0.22 \mathrm{nmol} / 1(0.76 \pm 0.17 \mathrm{ng} / \mathrm{ml})$ in those with atrial fibrillation.

Sixteen of the 46 patients deteriorated clinically while they were on placebo (table II). Three patients developed symptoms but no physical signs of deterioration, four had signs but not symptoms, and the remainder had both. Three patients (cases 8, 10, and 32) developed radiological evidence of pulmonary oedema. Deterioration occurred four days to three weeks after stopping digoxin. On resuming digoxin half of these patients recovered rapidly. In the other eight additional diuretic treatment was prescribed, but this was necessary for only a few weeks.

On placebo patients in both groups showed a significant increase in apex rate and a reduction in $\mathrm{FEV}_{1}$ and the ratio $\mathrm{FEV}_{1}: \mathrm{FVC}$. Systolic blood pressure decreased and body weight increased slightly only in group 1 (table III). Values returned to their baseline levels after digoxin was reintroduced, with additional diuretic when necessary. With the obvious exception of the serum digoxin concentration, there was no change in the biochemical values between the digoxin and placebo phases.

TABI.E III-Values on routine measurements made when patients were receiving digoxin and placebo. Values are means $\pm 1 S D$

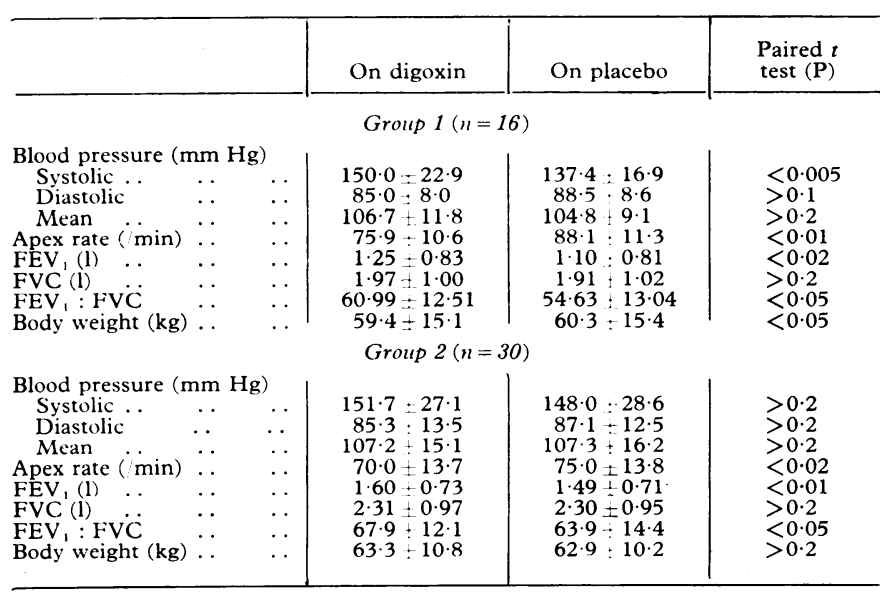

There was no significant difference between the groups in age, sex, cardiac rhythm, diagnosis, initial indication for digoxin, or diuretic treatment. The clinical assessment and routine measurements during the digoxin phase did not differentiate the groups.

Systolic time intervals-The QRS duration was normal (less than $100 \mathrm{~ms}$ ) in all nine patients. The $\mathrm{QS}_{2}, \mathrm{~S}_{1} \mathrm{~S}_{2}, \mathrm{LVET}$, and PEP intervals measured on placebo were not significantly different from those described in normal subjects. ${ }^{11}$ The $Q S_{2}$ and $S_{1} S_{2}$ and LVET intervals were shorter on digoxin (table IV). Since there was no difference in the PEP or its components, the change in LVET must account for the shortening of the $Q S_{2}$ and $S_{1} S_{2}$ (see Patients and Methods).

\section{Discussion}

The value of digoxin treatment after an episode of heart failure is disputed. ${ }^{12-14}$ The 46 clinically stable patients we studied had all been digitalised for this reason. Sixteen of these had increased symptoms or signs of heart failure on placebo. Increased pulmonary oedema was a prominent feature and was accompanied by an increase in airways resistance. The decrease in $\mathrm{FEV}_{1}$ seen in those who did not deteriorate clinically may have been a sign of incipient pulmonary oedema. Had the placebo phase been longer clinical deterioration may have occurred in this group.

The inotropic effect of digitalisation has been evaluated in cardiac disease of different causes and at various stages in the natural history, ${ }^{11}{ }^{15}$ but the effect of prolonged treatment has
TABLE IV-Effect of digoxin on systolic time intervals in nine patients from group 1. Values are means $\pm 1 S D$

\begin{tabular}{|c|c|c|c|c|}
\hline \multirow{2}{*}{\multicolumn{2}{|c|}{ Interval }} & \multicolumn{2}{|c|}{$\begin{array}{l}\text { Duration* } \\
(\mathrm{ms})\end{array}$} & \multirow{3}{*}{$\begin{array}{c}\begin{array}{c}\text { Paired } \\
t \text { test }\end{array} \\
P \\
<0.05 \\
<0.005 \\
<0.005 \\
>0.2\end{array}$} \\
\hline & & Placebo & Digoxin & \\
\hline $\begin{array}{l}\mathrm{QS}_{2} \\
\mathrm{~S}_{1} \mathrm{~S}_{2} \\
\mathrm{LVET} \\
\text { PEP }\end{array}$ & $\begin{array}{l}\ldots \\
\ldots \\
\ldots\end{array}$ & $\begin{array}{l}526: 50 \\
442: 23 \\
412: 26 \\
120: 15\end{array}$ & $\begin{array}{l}491 \div 56 \\
421: 25 \\
391 \div 27 \\
121 \div 29\end{array}$ & \\
\hline
\end{tabular}

*Corrected for heart rate and sex. ${ }^{10}$

been studied only in small highly selected groups in sinus rhythm. ${ }^{16-1 \times}$ In our study of nine patients from group 2 the LVET interval was shortened by digoxin by an amount similar to the maximum observed after an intravenous loading dose of digoxin. ${ }^{1920}$ Weissler et al ${ }^{10} 11$ showed that the reduction in LVET after a loading dose correlated with inotropic response. Our findings suggest that inotropism is sustained during maintenance treatment.

Much emphasis has been placed on the problems of achieving therapeutic serum digoxin concentrations. The accepted therapeutic range $(1 \cdot 3-2 \cdot 6 \mathrm{nmol} / 1(1 \cdot 0-2 \cdot 0 \mathrm{ng} / \mathrm{ml}))$ is based on the control of ventricular rate in atrial fibrillation ${ }^{21}$ and reduction of cardiotoxicity. 22 We have shown benefit at concentrations in the middle of this range in patients in sinus rhythm (average estimated mean steady state concentration $1.8 \mathrm{nmol} / 1(1.4 \mathrm{ng} /$ $\mathrm{ml})$ ) and in the lower part of the range in those with atrial fibrillation and impaired atrioventricular conduction (mean steady state concentration $1.4 \mathrm{nmol} / 1(1 \cdot 1 \mathrm{ng} / \mathrm{ml})$ ). When starting digoxin the use of simple guidelines ${ }^{23}$ should reduce the incidence of cardiotoxicity (about three quarters of the recommended dose should be used in "slow fibrillators") but will not avoid less serious manifestations of toxicity in the form of symptoms. ${ }^{24}$ During maintenance treatment measurement of the serum digoxin concentration is valuable both in ensuring that the desired concentration is achieved and in detecting noncompliant patients.

Diuretic treatment is also not without problems. ${ }^{25}$ Either hypokalaemia, due to diuretic therapy, or excess digitalis may cause arrhythmias, a combination of the two increasing the risk. Our findings showed the value of maintenance digoxin but cast some doubt on that of long-term diuretics. Although diuretics had to be introduced, or given in increased doses, in the eight patients in group 1 who did not recover rapidly on reintroduction of digoxin, they did not have to be continued for long. A study evaluating long-term diuretic treatment in a similar group of patients would seem to be indicated. In the light of the findings combined treatment could then be properly evaluated.

Mrs Elaine M Rodgers, supported by an MRC grant to Professor G E Mawer, carried out the digoxin radioimmunoassay. The staff of the physiological measurements and radiology departments, Tameside General Hospital, willingly undertook the extra work involved in the study. The placebo tablets were supplied by the Wellcome Clinical Department (UK and Ireland). SMD was supported by research grants from the North-west Regional Health Authority and the Wellcome Clinical Department.

\section{References}

1 Jelliffe, R W, and Brooker, G, American fournal of Medicine, 1974, 57, 63.

2 Beller, G A, et al, New England fournal of Medicine, 1971, 284, 989.

${ }^{3}$ Fogelman, A M, et al, Lancet, 1971, 2, 727.

4 Dobbs, S M, et al, British fournal of Clinical Pharmacology, 1976, 3, 231.

5 Rogen, A S, British Medical fournal, 1943, 1, 694.

6 Dall, J L C, British Medical fournal, 1970, 2, 705.

${ }^{7}$ Dobbs, S M, et al, British fournal of Clinical Pharmacology, 1976, 3, 940.

8 Wagner, J G, et al, Nature, 1965, 207, 1301.

9 Dobbs, S M, et al, British fournal of Clinical Pharmacology, 1976, 3, 674.

10 Weissler, A M, et al, Circulation, 1968, 37, 149.

11 Weissler, A M, and Schoenfeld, C D, American Fournal of Medical Sciences, 1970, 259, 4.

12 British Medical fournal, 1975, 1, 49. 
${ }^{13}$ Lancet, 1976, 2, 405

${ }^{14}$ Cohn, J N, Fournal of the American Medical Association, 1974, 229, 1911.

15 Marvin, H M, Fournal of Clinical Investigation, 19, 3, 521.

16 Kahler, R L, et al, Circulation, 1963, 27, 397.

17 Starr, I, and Luchi, R J, American Heart fournal, 1969, 78, 740.

18 Davidson, C, and Gibson, D, British Heart fournal, 1973, 35, 970.

19 Weissler, A M, et al, American fournal of Cardiology, 1966, 17, 768.

20 Shapiro, W, et al, Circulation, 1970, 42, 1065.
21 Chamberlain, D A, et al, British Medical fournal, 1970, 3, 429.

22 Smith, T W, and Haber, E, fournal of Clinical Investigation, 1970, 49, 2377.

23 Dobbs, S M, Lancet, 1976, 2, 694.

${ }^{24}$ Dobbs, S M, et al, British fournal of Clinical Pharmacology, in press.

${ }^{25}$ Prichard, B N C, and Tuckman, J, in Hypertension, Pathophysiology and Treatment, ed J Genest. Montreal, McGraw Hill, in press.

(Accepted 10 fanuary 1977)

\title{
Cholestyramine in uraemic pruritus
}

\author{
D S SILVERBERG, A IAINA, E REISIN, R ROTZAK, H E ELIAHOU
}

British Medical fournal, 1977, 1, 752-753

\section{Summary}

In a patient with longstanding severe uraemic pruritus who was undergoing chronic haemodialysis cholestyramine caused the pruritus to disappear completely within a few days. A four-week randomised controlled double-blind study was therefore performed in 10 other patients with uraemic pruritus who were on chronic haemodialysis. The pruritus improved considerably in four of the five treated patients, whereas only one of those treated with placebo experienced relief. The patient who had no relief while on cholestyramine showed a considerable improvement when the dose subsequently doubled. One of the five patients receiving cholestyramine experienced mild and easily reversible constipation, and another suffered nausea. Neither of these complications prevented the patients from continuing treatment. Cholestyramine seems to be useful in treating uraemic pruritus, although it is not known how it acts.

\section{Introduction}

Pruritus is common in uraemic patients, and although it may improve after dialysis has been started in some cases, in others it may persist and even worsen. We recently administered cholestyramine (Cuemid), an anion-exchange resin, in a dose of $5 \mathrm{~g}$ twice daily by mouth, to a patient on chronic haemodialysis who had longstanding severe uraemic pruritus. Within three days his pruritus had greatly diminished, and by one week it had disappeared entirely. He remained free of pruritus for the next month while on the drug. When it was discontinued pruritus returned within three days but disappeared again three days after restarting it. At the time of writing he had been on the drug continually for two months and the pruritus had not returned. Our favourable experience with this patient prompted us to perform a randomised double-blind controlled study of oral cholestyramine in 10 other patients undergoing chronic haemodialysis who also suffered from pruritus.

\footnotetext{
Department of Nephrology, Sheba Medical Centre, Tel Hashomer, Israel

D S SILVERBERG, MD, visiting professor of nephrology, University of Tel-Aviv

A IAINA, MD, senior nephrologist

E REISIN, MD, senior nephrologist

R ROTZAK, $M D$, resident in internal medicine

H E ELIAHOU, MD, head of department of nephrology
}

\section{Patients and methods}

Ten men with longstanding pruritus were studied. All were undergoing haemodialysis for three to five hours three times a week on either a Dow-Cordis hollow-fibre No 5 dialyser or a Travenol Ultra-Flo No 2 dialyser. All were taking a diet containing $1 \mathrm{~g}$ protein/ $\mathrm{kg}$ body weight/day. Those with raised serum phosphate concentrations were taking aluminium hydroxide by mouth. None had jaundice, liver disease, or hypercalcaemia, and none had had a parathyroidectomy.

The 10 patients were randomly assigned to two treatments: five took cholestyramine $5 \mathrm{~g}$ twice daily in juice, and five took a placebo (methylcellulose) in the same dose. The trial lasted for four weeks. For three weeks before the trial and during the four-week trial all patients recorded the severity of their pruritus every day. Points were given for the degree of pruritus: $0=$ none; $1=$ slight; $2=$ moderate; $3=$ great. We calculated a daily pruritus score before and after treatment for each patient by taking the mean of all the daily scores. Thus the score for the three weeks before treatment was the mean of 21 days' values and the score during treatment was the mean of 28 days' values.

The following routine laboratory investigations were performed before dialysis just before the start of treatment with drug and placebo and again at the end of the trial: prothrombin time was measured and blood urea and serum creatinine, sodium, potassium, chloride, bicarbonate, calcium, phosphate, alkaline phosphatase, albumin, cholesterol, and triglyceride concentrations were determined.

\section{Results}

During the three-week pretrial period all 10 patients complained of pruritus of varying degrees (see table). During the four-week

Mean daily pruritus score before and after treatment. Highest score possible is 3

\begin{tabular}{|c|c|c|c|c|c|c|c|c|c|c|}
\hline \multicolumn{6}{|c|}{ Patients on cholestyramine } & \multicolumn{5}{|c|}{ Patients on placebo } \\
\hline $\begin{array}{l}\text { Case } \\
\text { No: }\end{array}$ & 1 & 2 & 3 & 4 & 5 & 6 & 7 & 8 & 9 & 10 \\
\hline $\begin{array}{l}\text { Before } \\
\text { After }\end{array}$ & $\begin{array}{l}1 \cdot 9 \\
2 \cdot 0\end{array}$ & $\begin{array}{l}2 \cdot 2 \\
0.9\end{array}$ & $\begin{array}{l}2 \cdot 3 \\
1 \cdot 2\end{array}$ & $\begin{array}{l}1.9 \\
1.0\end{array}$ & $\begin{array}{l}1.9 \\
0.3\end{array}$ & $\begin{array}{l}1.9 \\
1.9\end{array}$ & $\begin{array}{l}0.9 \\
0.5\end{array}$ & $\begin{array}{l}2 \cdot 1 \\
2 \cdot 3\end{array}$ & $\begin{array}{l}1.2 \\
1.2\end{array}$ & $\begin{array}{l}2 \cdot 2 \\
2 \cdot 3\end{array}$ \\
\hline
\end{tabular}

treatment period four of the five cholestyramine-treated patients noted a reduction in pruritus. In one (case 5) pruritus disappeared entirely and in the other 3 (cases 2-4) it decreased considerably. In all four cases pruritus started to improve within four days and showed its greatest improvement after one to two weeks. After the four-week study the patient who had shown no change on cholestyramine (case 1) was given $5 \mathrm{~g}$ four times daily, and his pruritus improved greatly within four days and was minimal thereafter.

One patient (case 4) had developed severe constipation by the fourth day of treatment with cholestyramine. This improved after he was given daily doses of a mild laxative. He continued the treatment 